\title{
Fear During COVID-19 pandemic: Fear of COVID-19 Scale Measurement Properties
}

\author{
Irfan Ullah, et al. [full author details at the end of the article]
}

Accepted: 13 March 2021/ Published online: 3 September 2021

(C) The Author(s), under exclusive licence to Springer Science+Business Media, LLC, part of Springer Nature 2021

\section{Dear Editor,}

The emergence and development of the COVID-19 pandemic is having a toll on the mental health of the general population, and healthcare workers around the world, often manifested in depression, fear, stress, trauma, and anxiety (Ahorsu et al. 2020; Mamun and Ullah 2020; Lee et al, 2020). Various scales have been developed during the pandemic to measure these effects (Ransing et al. 2020). Fear during the COVID-19 pandemic has been associated with serious mental health consequences, such as passive suicidal ideation, alcohol and substance use, and extreme hopelessness (Mamun and Ullah 2020). Hence, a timely and accurate assessment of COVID-19-related fear is relevant for clinicians.

The Fear of COVID-19 Scale (FCV-19S) is a 7-item scale that assesses the severity of COVID-19-related fear (Ahorsu et al. 2020). Each item is rated on a 5-point Likert scale: 1 (strongly disagree) to 5 (strongly agree), with higher scores indicating a greater fear of COVID-19 (Ahorsu et al. 2020). The tool was developed in Persian language, and its initial validation was conducted in a sample of Iranian adults drawn from the general population. Following the initial validation, several studies have examined the psychometric properties of the scale across different populations and in different languages (Ransing et al. 2020). In this letter, we provide an overview of the available literature on the utility and psychometric properties of the FCV-19S.

We searched PubMed using the keywords "COVID-19" or "SARS-CoV-2" or "Coronavirus disease" and "Fear Scale" or "FCV-19S" or "Fear of COVID-19 Scale" till 30 August 2020. We found 19 studies assessing the reliability and/or validity of the FCV-19S. The full texts for each article were retrieved and data extracted regarding sample size, mean age, language, country, and scale reliability and validity. A summary of the included studies is presented in Table 1 .

The FCV-19S has been translated into 14 languages and validated across 20 different countries (Pakpour et al, 2020). Three studies, including the initial validation study, were conducted in the Middle East, six in Asia, six in Europe, and one each in the USA, New Zealand, Cuba, and Peru. Most of the studies $(n=18)$ validated the FCV-19S with adult populations, with one study being conducted among adolescents. The Cronbach's alpha values across the different studies ranged from 0.81 to 0.93 indicating high reliability of the FCV-19S.

Twelve studies investigated the criterion validity (either discriminant or convergent) of the FCV19S. Similarly to the original validation (Ahorsu et al. 2020), Soraci et al. and Alyami et al. examined the validity of the FCV-19S against the HADS among Italian and Saudi Arabian adults, 


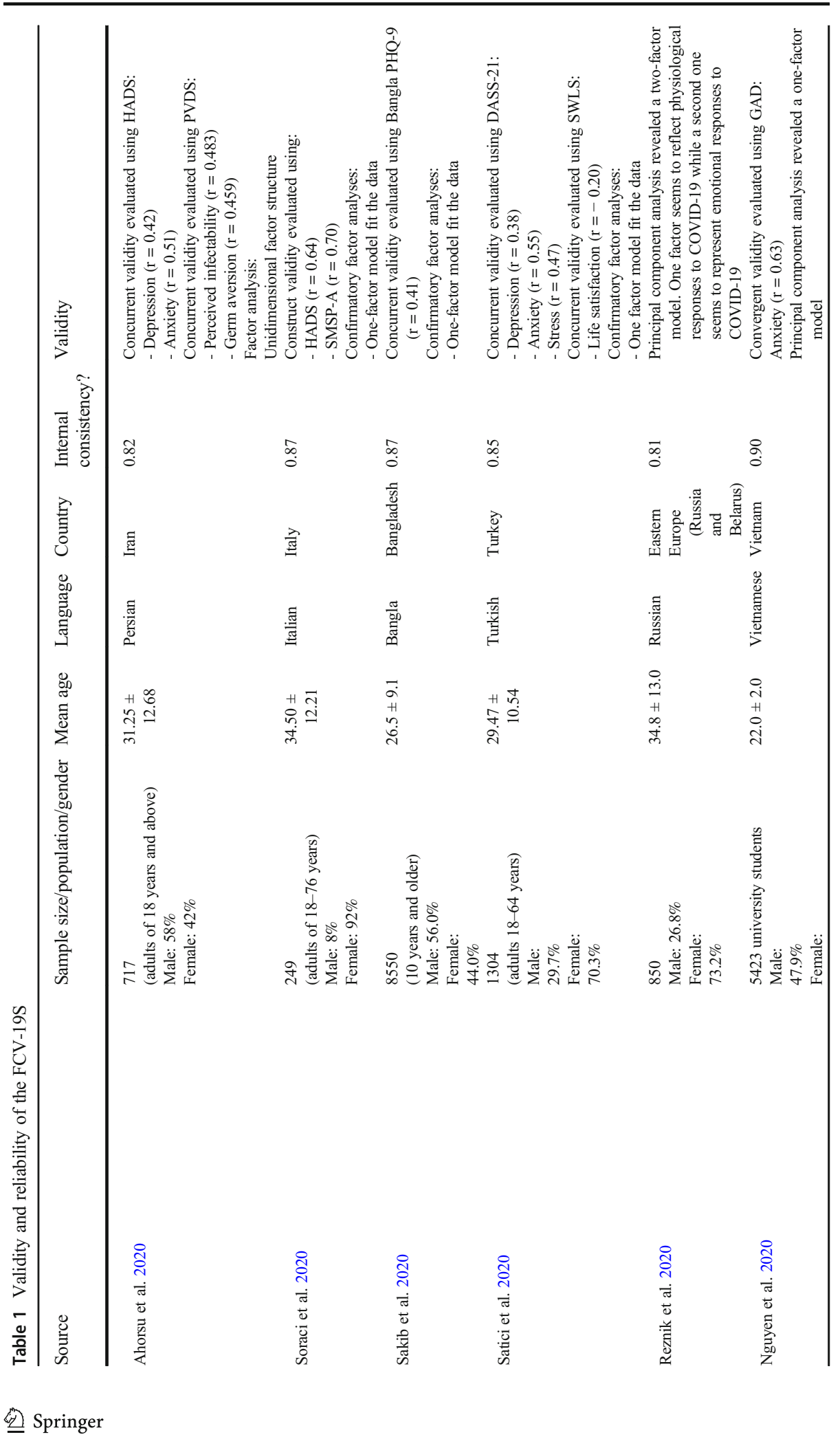




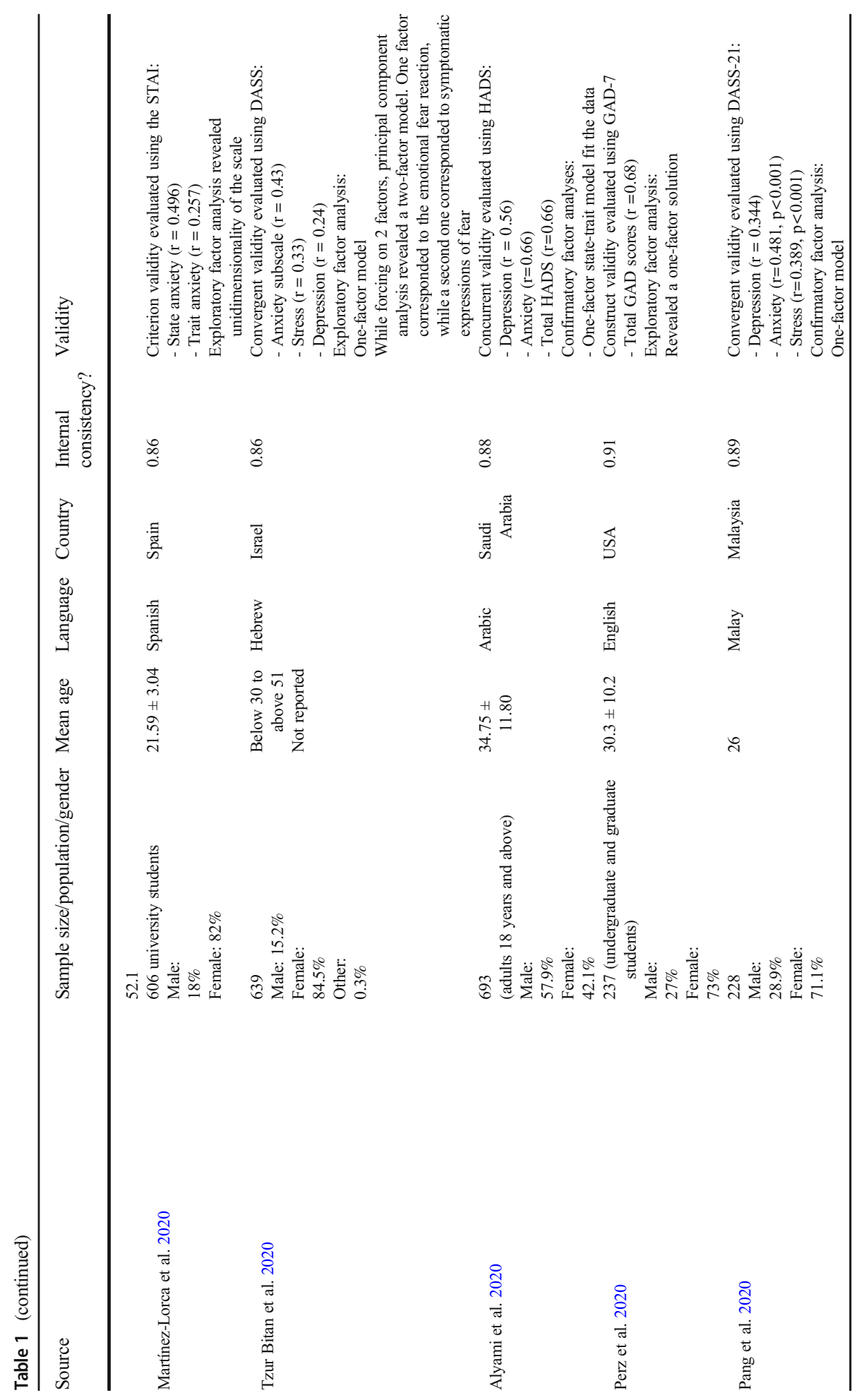




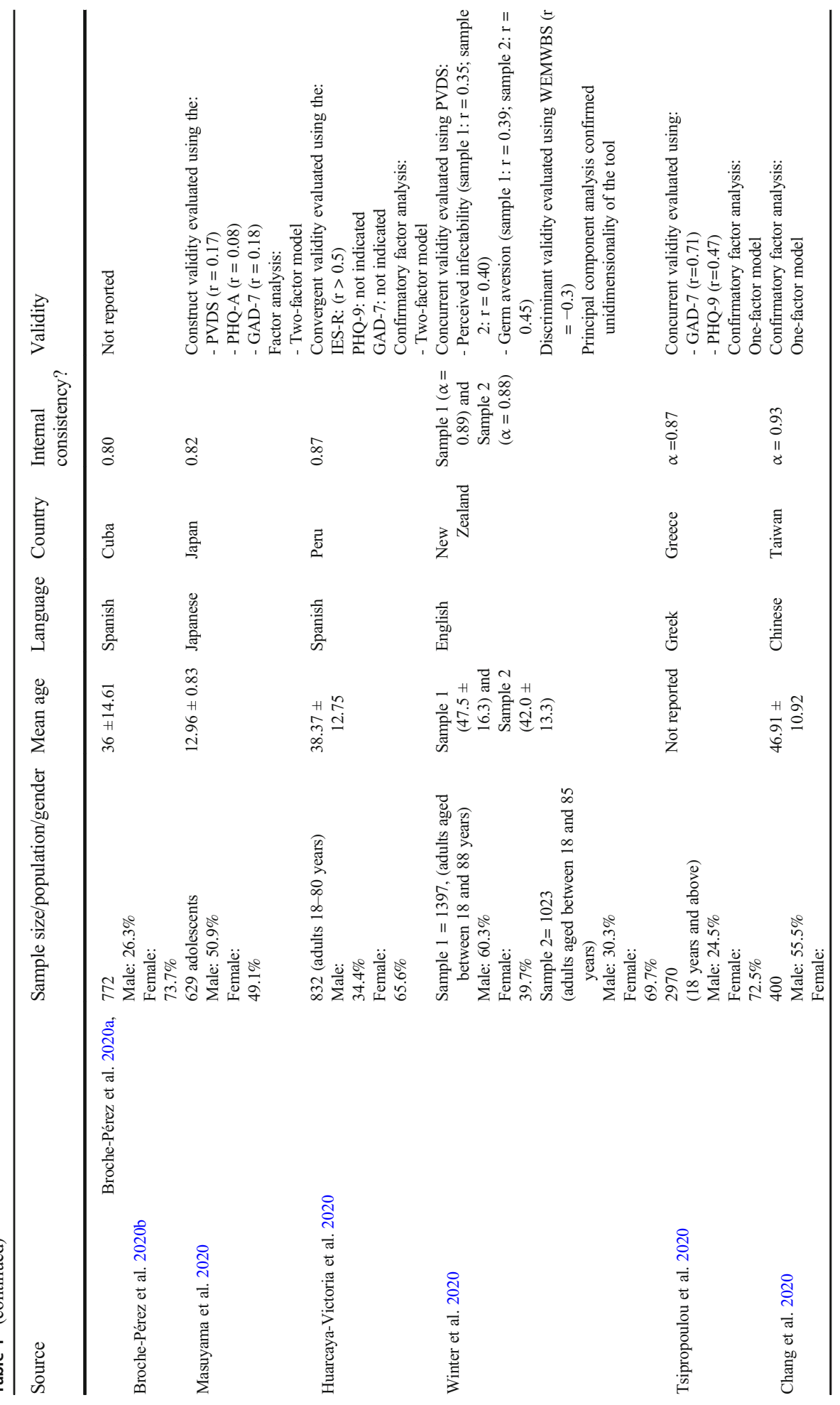




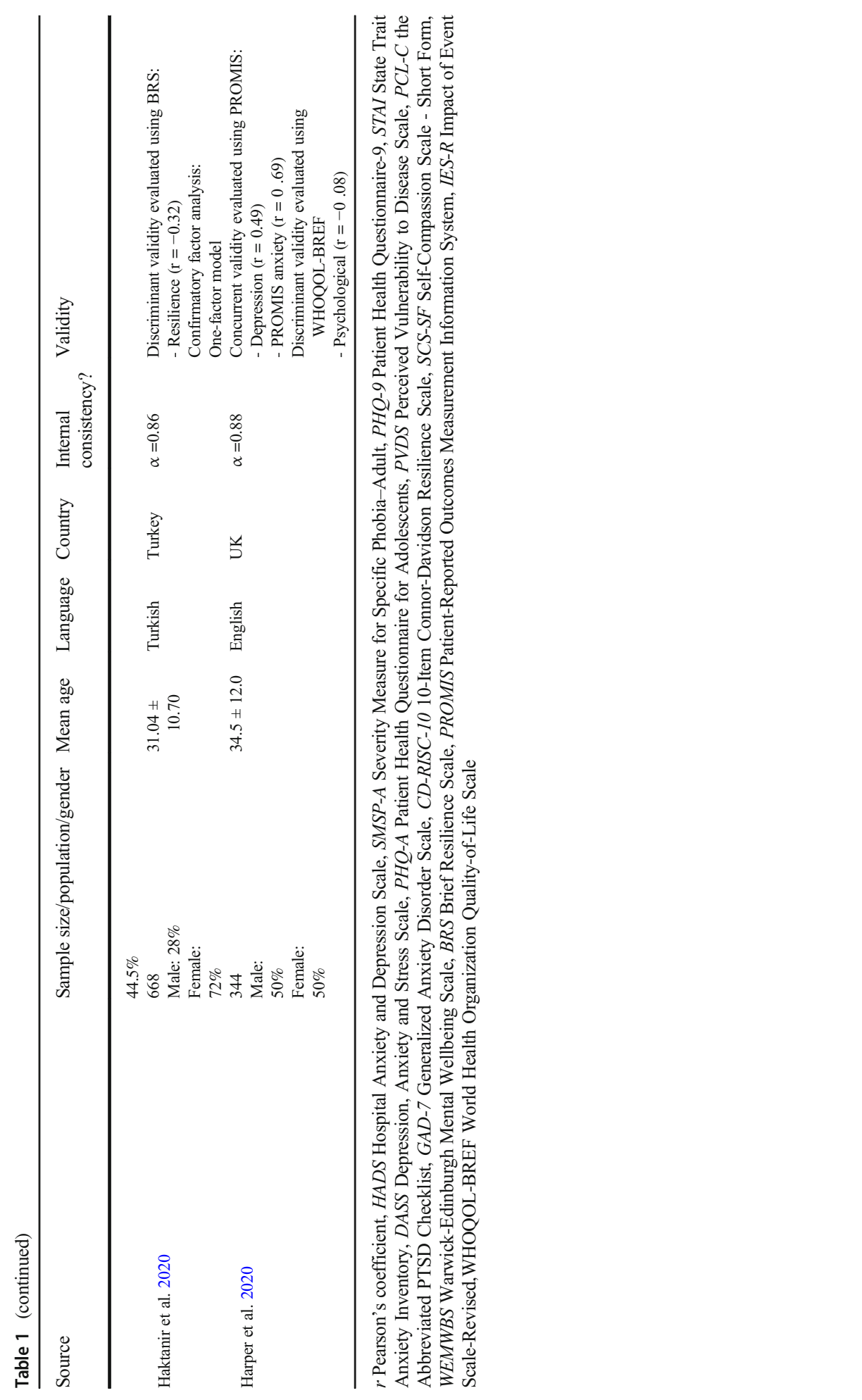


respectively (Soraci et al. 2020; Alyami et al. 2020). They both found the FCV-19S to be valid with acceptable correlation values of 0.64 and 0.66 , respectively. Also, Winter et al. (2020) confirmed the validity of the FCV-19S in two samples of New Zealand adults using the PVDS (Winter et al. 2020). Other studies that examined and confirmed the convergent validity of the FCV-19S among adults used various anxiety and depression measures (Sakib et al. 2020; Satici et al. 2020; Pang et al. 2020; Martínez-Lorca et al. 2020). Further support for the criterion validity of the FCV-19S among adults came from findings indicating acceptable correlation coefficient values for discriminant validity $(-0.32$ to -0.08$)$.

Among younger populations, findings are inconsistent. Martínez-Lorca et al. compared FCV$19 \mathrm{~S}$ scores with those of the STAI among Spanish undergraduate students (Martínez-Lorca et al. 2020). The authors found a positive correlation with state anxiety $(r=0.496)$, but not with trait anxiety $(r=0.257)$. Similarly, Perz et al. validated the FCV-S19 using the GAD-7 in university students in the USA and found positive correlations between the FCV-19S and the GAD-7 $(r=0.68)$ (Perz et al. 2020). In the only study conducted in an adolescent population, Masuyama et al. examined the construct validity of the FCV and reported poor correlation coefficient values of FCV19S against the PVDS ( $\mathrm{r}=0.17$ ), the PHQ-9 modified for Adolescents (PHQ-A) (r=0.08), and GAD7 ( $r=0.18$ ) ( Masuyama et al. 2020).

Three studies conducted in Japan (Masuyama et al. 2020), Peru (Huarcaya-Victoria et al. 2020), and Russia and Belarus (Reznik et al. 2020) examined the factor structure of the FCV-19S. All three studies reported the factor structure of the FCV-19S to be consistent with a two-factor model. Furthermore, the loadings on the factor were significant and strong (from 0.684 to 0.897) (Soraci et al. 2020). The results showed that seven items of the FCV-19S strongly loaded on one component and explained $62.15 \%$ of the variance (Nguyen et al. 2020). Finally, the findings of factor analysis varied across populations. While a majority of the studies confirmed the unidimensionality of the scale as reported in the initial validation study, some authors reported their respective data to be consistent with a two-factor solution (Huarcaya-Victoria et al. 2020; Masuyama et al. 2020; Reznik et al. 2020). However, one study on exploratory factor analysis confirms one factor model but forcing on two factors (Tzur Bitan et al. 2020).

Overall, the findings of this review confirm the reliability, criterion, and construct validity of the FCV-19S for adults across multiple populations around the world. However, findings in younger populations are inconsistent. Future research ought to examine the usefulness of this FCV-19S in the real context in terms of cost-effectiveness, efficiency, and correlation with actual psychiatric disorders.

\section{Declarations}

Conflict of interest The authors declare that they do not have conflict of interest.

Ethical Statement Not applicable.

Statement of Human Rights Not applicable.

Ethical Approval Not applicable.

Informed Consent Not applicable. 


\section{References}

Ahorsu, D. K., Lin, C. Y., Imani, V., Saffari, M., Griffiths, M. D., \& Pakpour, A. H. (2020). The fear of COVID19 scale: Development and initial validation. International Journal of Mental Health and Addiction, 1-9. Advance online publication. https://doi.org/10.1007/s11469-020-00270-8

Alyami, M., Henning, M., Krägeloh, C. U., \& Alyami, H. (2020). Psychometric evaluation of the Arabic version of the fear of COVID-19 scale. International Journal of Mental Health and Addiction, 1-14. Advance online publication. https://doi.org/10.1007/s11469-020-00316-X

Broche-Pérez, Y., Fernández-Fleites, Z., Jiménez-Puig, E., Fernández-Castillo, E., \& Rodríguez-Martin, B. C. (2020a). Gender and fear of COVID-19 in a Cuban population sample. International Journal of Mental Health and Addiction, 1-9. Advance online publication. https://doi.org/10.1007/s11469-020-00343-8

Broche-Pérez, Y., Fernández-Fleites, Z., Jiménez-Puig, E., Fernández-Castillo, E., \& Rodríguez-Martin, B. C. (2020b). Correction to: Gender and fear of COVID-19 in a Cuban population sample. International Journal of Mental Health and Addiction, 1. Advance online publication. https://doi.org/10.1007/s11469-020-00377$\mathrm{y}$

Chang, K. C., Hou, W. L., Pakpour, A. H., Lin, C. Y., \& Griffiths, M. D. (2020). Psychometric testing of three COVID-19-related scales among people with mental illness. International Journal of Mental Health and Addiction, 1-13. Advance online publication. https://doi.org/10.1007/s11469-020-00361-6

Haktanir, A., Seki, T., \& Dilmaç, B. (2020). Adaptation and evaluation of Turkish version of the fear of COVID19 scale. Death studies, 1-9. Advance online publication. https://doi.org/10.1080/07481187.2020.1773026

Harper, C. A., Satchell, L. P., Fido, D., \& Latzman, R. D. (2020). Functional fear predicts public health compliance in the COVID-19 pandemic. International journal of Mental Health and Addiction, 1-14. Advance online publication. https://doi.org/10.1007/s11469-020-00281-5

Huarcaya-Victoria, J., Villarreal-Zegarra, D., Podestà, A., \& Luna-Cuadros, M. A. (2020). Psychometric properties of a spanish version of the fear of COVID-19 scale in general population of Lima, Peru. International Journal of Mental Health and Addiction, 1-14. Advance online publication. https://doi.org/ 10.1007/s11469-020-00354-5

Masuyama, A., Shinkawa, H., \& Kubo, T. (2020). Validation and psychometric properties of the Japanese version of the fear of COVID-19 scale among adolescents. International Journal of Mental Health and Addiction, 1-11. Advance online publication. https://doi.org/10.1007/s11469-020-00368-Z

Pang, N., Kamu, A., Hambali, N., Mun, H. C., Kassim, M. A., Mohamed, N. H., Ayu, F., Rahim, S., Omar, A., \& Jeffree, M. S. (2020). Malay version of the fear of COVID-19 scale: Validity and reliability. International Journal of Mental Health and Addiction, 1-10. Advance online publication. https://doi.org/10.1007/s11469020-00355-4

Perz, C. A., Lang, B. A., \& Harrington, R. (2020). Validation of the fear of COVID-19 scale in a US college sample. International Journal of Mental Health and Addiction, 1-11. Advance online publication. https:// doi.org/10.1007/s11469-020-00356-3

Ransing, R., Ramalho, R., Orsolini, L., Adiukwu, F., Gonzalez-Diaz, J. M., Larnaout, A., Pinto da Costa, M., Grandinetti, P., Bytyçi, D. G., Shalbafan, M., Patil, I., Nofal, M., Pereira-Sanchez, V., \& Kilic, O. (2020). Can COVID-19 related mental health issues be measured? Brain, Behavior, and Immunity, 88, 32-34. https://doi.org/10.1016/j.bbi.2020.05.049

Reznik, A., Gritsenko, V., Konstantinov, V., Khamenka, N., \& Isralowitz, R. (2020). COVID-19 fear in Eastern Europe: Validation of the fear of COVID-19 scale. International Journal of Mental Health and Addiction, 16. Advance online publication. https://doi.org/10.1007/s11469-020-00283-3

Sakib, N., Bhuiyan, A., Hossain, S., Al Mamun, F., Hosen, I., Abdullah, A. H., Sarker, M. A., Mohiuddin, M. S., Rayhan, I., Hossain, M., Sikder, M. T., Gozal, D., Muhit, M., Islam, S., Griffiths, M. D., Pakpour, A. H., \& Mamun, M. A. (2020). Psychometric validation of the bangla fear of COVID-19 scale: Confirmatory factor analysis and rasch analysis. International Journal of Mental Health and Addiction, 1-12. Advance online publication. https://doi.org/10.1007/s11469-020-00289-x

Satici, B., Gocet-Tekin, E., Deniz, M. E., \& Satici, S. A. (2020). Adaptation of the fear of COVID-19 scale: Its association with psychological distress and life satisfaction in Turkey. International Journal of Mental Health and Addiction, 1-9. Advance online publication. https://doi.org/10.1007/s11469-020-00294-0

Soraci, P., Ferrari, A., Abbiati, F. A., Del Fante, E., De Pace, R., Urso, A., \& Griffiths, M. D. (2020). Validation and psychometric evaluation of the italian version of the fear of COVID-19 scale. International Journal of Mental Health and Addiction, 1-10. Advance online publication. https://doi.org/10.1007/s11469-02000277-1

Tsipropoulou, V., Nikopoulou, V. A., Holeva, V., Nasika, Z., Diakogiannis, I., Sakka, S., Kostikidou, S., Varvara, C., Spyridopoulou, E., \& Parlapani, E. (2020). Psychometric properties of the Greek version of FCV-19S. International Journal of Mental Health and Addiction, 1-10. Advance online publication. https:// doi.org/10.1007/s1 1469-020-00319-8 
Winter, T., Riordan, B. C., Pakpour, A. H., Griffiths, M. D., Mason, A., Poulgrain, J. W., \& Scarf, D. (2020). Evaluation of the english version of the fear of COVID-19 scale and its relationship with behavior change and political beliefs. International Journal of Mental Health and Addiction, 1-11. Advance online publication. https://doi.org/10.1007/s11469-020-00342-9

Sakib, N., Bhuiyan, A.K.M.I., Hossain, S., al Mamun F., Hosen I., Abdullah A.H., Sarker M.A., Mohiuddin M.S., Rayhan I., Hossain M., Sikder M.T., Gozal D., Muhit M., Islam S.M.S., Griffiths M.D., Pakpour A.H., Mamun M.A. Psychometric validation of the Bangla Fear of COVID-19 Scale: Confirmatory factor analysis and Rasch analysis. Int J Ment Health Addiction (2020). https://doi.org/10.1007/s11469-020-00289-x

Satici, B., Gocet-Tekin, E., Deniz, M.E., Satici S.A. Adaptation of the Fear of COVID-19 Scale: Its association with psychological distress and life satisfaction in Turkey. Int J Ment Health Addiction (2020). https://oi. org/10.1007/s11469-020-00294-0

Soraci, P., Ferrari, A., Abbiati, F.A., del Fante E., de Pace R., Urso A., Griffiths M.D. Validation and psychometric evaluation of the Italian version of the Fear of COVID-19 Scale. Int J Ment Health Addiction (2020). https://doi.org/10.1007/s11469-020-00277-1

Tsipropoulou, V., Nikopoulou, V. A., Holeva, V., Nasika, Z., Diakogiannis, I., Sakka, S., Kostikidou, S., Varvara, C., Spyridopoulou, E., \& Parlapani, E. (2020). Psychometric properties of the Greek version of FCV-19S. International Journal of Mental Health and Addiction, 1-10. Advance online publication. https:// doi.org/10.1007/s11469-020-00319-8.

Tzur Bitan, D., Grossman-Giron, A., Bloch, Y., Mayer, Y., Shiffman, N., \& Mendlovic, S. (2020). Fear of COVID-19 scale: Psychometric characteristics, reliability and validity in the Israeli population. Psychiatry Research, 289, 113100. https://doi.org/10.1016/j.psychres.2020.113100.

Winter, T., Riordan, B.C., Pakpour, A.H., Griffiths M.D., Mason A., Poulgrain J.W., Scarf D. Evaluation of the English version of the Fear of COVID-19 Scale and its relationship with behavior change and political beliefs. Int J Ment Health Addiction (2020). https://doi.org/10.1007/s11469-020-00342-9

Publisher's Note Springer Nature remains neutral with regard to jurisdictional claims in published maps and institutional affiliations.

\section{Affiliations}

Irfan Ullah ${ }^{1} \cdot$ Florence Jaguga $^{2} \cdot$ Ramdas Ransing $^{3} \cdot$ Victor Pereira-Sanchez $^{4} \cdot$ Laura $^{-}$ Orsolini $^{5}$ - Dorottya Ori ${ }^{6} \cdot$ Renato de Filippis $^{7} \cdot$ Amir H Pakpour $^{8,28} \cdot$ Frances Adiukwu $^{9}$ • Ozge Kilic ${ }^{10}$. Nafisatu Hayatudeen ${ }^{11}$. Sheikh Shoib ${ }^{12}$ - Margaret Isioma Ojeahere $^{13}$. Sachin Nagendrappa ${ }^{14}$ • Jibril I.M Handuleh ${ }^{15}$ • Elona Dashi ${ }^{16}$. Umar Baba Musami $^{17} \cdot$ Bita Vahdani $^{18} \cdot$ Agaah Ashrafi $^{19} \cdot$ Chonnakarn Jatchavala $^{20} \cdot$ Zargham $^{2}$ Abbass $^{21}$ - Sarah El Halabi ${ }^{22}$. Oluseun Peter OGUNNUBI ${ }^{23}$ - Mariana Pinto da Costa $^{24,25,26} \cdot$ Rodrigo Ramalho ${ }^{27}$

Irfan Ullah

irfanullahecp2@gmail.com

Amir H Pakpour

Amir.Pakpour@ju.se

Florence Jaguga

flokemboi@gmail.com

Ramdas Ransing

ramdas_ransing123@yahoo.co.in

Victor Pereira-Sanchez

vpereira@alumni.unav.es

Laura Orsolini

laura.orsolini01@gmail.com 
Dorottya Ori

oridorottya@gmail.com

Renato de Filippis

defilippisrenato@gmail.com

Frances Adiukwu

francesadiukwu@gmail.com

Ozge Kilic

drozgekilic@gmail.com

Nafisatu Hayatudeen

nhayatudeen@gmail.com

Sheikh Shoib

Sheikshoib22@gmail.com

Margaret Isioma Ojeahere

margaret.ojeahere@gmail.com

Sachin Nagendrappa

nsachin40@gmail.com

Jibril I.M Handuleh

Jibril.ibrahim@sphmmc.edu.et

Elona Dashi

elonadashi@gmail.com

Umar Baba Musami

ubmusami@gmail.com

Bita Vahdani

bita.vahdani@gmail.com

Agaah Ashrafi

agahashrafi@gmail.com

Chonnakarn Jatchavala

jchonnak@medicine.psu.ac.th

Zargham Abbass

z.abbass.umkc@gmail.com

Sarah El Halabi

se2507@ columbia.edu

Oluseun Peter OGUNNUBI

onubi@unilag.edu.ng

Mariana Pinto da Costa

mariana.pintodacosta@gmail.com

Rodrigo Ramalho

r.ramalho@auckland.ac.nz

Kabir Medical College, Gandhara University, Peshawar, Pakistan

2 Moi Teaching \& Referral Hospital, Eldoret, Kenya

3 Department of Psychiatry, BKL Walawalkar Rural Medical College, Ratnagiri, Maharashtra 415606, India 
4 Department of Child and Adolescent Psychiatry, NYU Grossman School of Medicine, New York, USA

5 Unit of Clinical Psychiatry, Department of Neurosciences/DIMSC, School of Medicine, Polytechnic University of Marche, 60126 Ancona, Italy

6 Department of Mental Health, Heim Pal National Pediatric Institute, Budapest, Hungary

7 Psychiatric Unit, Department of Health Sciences, University Magna Graecia of Catanzaro, 88100 Catanzaro, Italy

8 Social Determinants of Health Research Center, Research Institute for Prevention of Non-Communicable Diseases, Qazvin University of Medical Sciences, Shahid Bahounar BLV, Qazvin 3419759811, Iran

9 Department of Mental Health, University of Port Harcourt, Port Harcourt, Rivers state, Nigeria

10 Department of Psychiatry, Bezmialem Vakif University, Faculty of Medicine, Istanbul, Turkey

11 Federal Neuropsychiatric Hospital, Kaduna, Nigeria

12 Independent Public Health and Clinical Researcher, Mind Wellness Center, Nawab bazar, Srinagar, Kashmir, India

13 Department of Psychiatry, Jos University Teaching Hospital, Jos, Plateau State, Nigeria

14 National Institute of Mental Health and Neurosciences, Bengaluru, India

15 Saint Paul's Hospital Millennium Medical College, Addis Ababa, Ethiopia

16 Department of Neuroscience, University Hospital Center "Mother Theresa", Tirana, Albania

17 University of Maiduguri /Federal Neuropsychiatric Hospital Maiduguri, Maiduguri, Nigeria

18 Clinical Research Development Unit, 22 Bahman Hospital, Qazvin University of Medical Sciences, Qazvin, Iran

19 Psychiatry Department, Tehran University of Medical Sciences, Roozbeh Hospital, Tehran, Iran

20 Department of Psychiatry, Faculty of Medicine, Prince of Songkla University, Songkhla, Thailand

21 University of Missouri-Kansas City, Kansas City, USA

22 Psychiatry Department, Westchester Medical Center, Valhalla, New York, USA

23 College of Medicine, University of Lagos, Lagos, Nigeria

24 Institute of Psychiatry, Psychology \& Neuroscience, King's College London, London, UK

25 Institute of Biomedical Sciences Abel Salazar, University of Porto, Porto, Portugal

26 South London and Maudsley NHS Foundation Trust, London, UK

27 Department of Social and Community Health, School of Population Health, University of Auckland, Auckland, New Zealand

28 Department of Nursing, School of Health and Welfare, Jönköping University, Jönköping, Sweden 